\title{
Space Shuttle Day-of-Launch Trajectory Design Operations
}

\author{
Brian E. Harrington ${ }^{1}$ \\ United Space Alliance, LLC, Houston, TX 77058
}

\begin{abstract}
A top priority of any launch vehicle is to insert as much mass into the desired orbit as possible. This requirement must be traded against vehicle capability in terms of dynamic control, thermal constraints, and structural margins. The vehicle is certified to specific structural limits which will yield certain performance characteristics of mass to orbit. Some limits cannot be certified generically and must be checked with each mission design. The most sensitive limits require an assessment on the day-of-launch. To further minimize vehicle loads while maximizing vehicle performance, a day-of-launch trajectory can be designed. This design is optimized according to that day's wind and atmospheric conditions, which increase the probability of launch. The day-of-launch trajectory design and verification process is critical to the vehicle's safety.
\end{abstract}

The Day-Of-Launch I-Load Update (DOLILU) is the process by which the National Aeronautics and Space Administration's (NASA) Space Shuttle Program tailors the vehicle steering commands to fit that day's environmental conditions and then rigorously verifies the integrated vehicle trajectory's loads, controls, and performance. This process has been successfully used for almost twenty years and shares many of the same elements with other launch vehicles that execute a day-of-launch trajectory design or day-of-launch trajectory verification. Weather balloon data is gathered at the launch site and transmitted to the Johnson Space Center's Mission Control. The vehicle's first stage trajectory is then adjusted to the measured wind and atmosphere data. The resultant trajectory must satisfy loads and controls constraints. Additionally, these assessments statistically protect for nonobserved dispersions. One such dispersion is the change in the wind from the last measured balloon to launch time. This process is started in the hours before launch and is repeated several times as the launch count proceeds. Should the trajectory design not meet all constraint criteria, Shuttle would be No-Go for launch.

This Shuttle methodology is very similar to other unmanned launch vehicles. By extension, this method would likely be employed for any future NASA launch vehicle. This paper will review the Shuttle's day-of-launch trajectory optimization and verification operations as an example of a more generic application of day-of-launch design and validation. With Shuttle's retirement, it is fitting to document the current state of this critical process and capture lessons learned to benefit current and future launch vehicle endeavors.

Copyright $\odot 2011$ by United Space Alliance, LLC. These materials are sponsored by the National Aeronautics and Space Administration under Contract NNJ06VA01C. The U.S. Government retains a paid-up, nonexclusive, irrevocable worldwide license in such materials to reproduce, prepare, derivative works, distribute copies to the public, and perform publicly and display publicly, by or on behalf of the U.S. Government. All other rights are reserved by the copyright owner.

\footnotetext{
${ }^{1}$ Engineering Staff, Ascent/Descent Flight Design, Mail Code: USH-482L, 600 Gemini Ave.
} 


\title{
Space Shuttle Day-of-Launch Trajectory Design Operations
}

\author{
Brian E. Harrington ${ }^{1}$ \\ United Space Alliance, LLC, Houston, TX 77058 \\ Bret A. Picka ${ }^{2}$ \\ United Space Alliance, LLC, Houston, TX 77058 \\ Henry S. Cordova ${ }^{3}$ \\ NASA Johnson Space Center, Houston, TX 77058
}

\begin{abstract}
A top priority of any launch vehicle is to safely and reliably insert as much mass into the desired orbit as possible. Some structural constraints cannot be certified generically and must be checked with each mission design. The most sensitive constraints require an assessment on the day-of-launch. To further minimize vehicle structural loading while maximizing vehicle performance, a day-of-launch trajectory must be designed. The Day-OfLaunch I-Load Update (DOLILU) is the process by which the National Aeronautics and Space Administration's (NASA) Space Shuttle Program tailors the vehicle steering commands to fit that day's environmental conditions and then rigorously verifies the integrated vehicle trajectory's loads, controls, and performance. This process has been successfully used for almost twenty years and shares many of the same elements with other launch vehicles. This paper will review the current state of the Shuttle's day-of-launch trajectory optimization and verification operations to benefit current and future launch vehicle endeavors.
\end{abstract}

\section{Introduction}

$\mathrm{W}$ ITH the final Space Shuttle launch on July 8th, 2011, the National Aeronautics Space Administration (NASA) saw the final execution of a just-in-time trajectory design and validation process. The trajectory was not planned months or even days before launch, but rather was tailored to the specific atmospheric conditions of the day. The Space Shuttle successfully experienced vehicle structural loading well within capability. The duty to center the vehicle structural constraints while optimizing mission success is completed by a robust trajectory design and verification system. Sixty-six consecutive shuttle launches have successfully utilized the same methodology. Most space vehicles must design their trajectory to the atmospheric conditions of the day in order to recenter vehicle loads and maximize launch opportunities. The Space Shuttle has used the Day-of-Launch Initialization Load Update, or DOLILU, system for this safety critical trajectory design and verification task.

\footnotetext{
${ }^{1}$ Ascent Flight Design Specialist, Flight Dynamics Division, Mail Code USH-482L, 600 Gemini Ave.

${ }^{2}$ Aerospace Engineer, Flight Dynamics Division, Mail Code USH-482L, 600 Gemini Ave.

${ }^{3}$ Aerospace Engineer, Flight Dynamics Division, Mail Code DM44, 2101 NASA Parkway
} 


\section{Process Overview}

The Space Shuttle guidance is broken into two stages: the first, from liftoff to Solid Rocket Booster (SRB) separation and the second, from staging to main engine cutoff (MECO). The first stage guidance is open-loop, while the second stage is closed-loop. The first stage is flying specific steering commands developed by ground software to meet specific staging criteria and minimize sensed loads. The second stage closed-loop guidance cyclically computes the thrust vector required to execute a fuel-optimal trajectory to a specific MECO target that is defined by a specific terminal velocity, inertial flight path angle, altitude, and desired orbital plane. The MECO target is not constrained in the downrange direction.

First stage flight includes a region from near sea level to an altitude of approximately 155,000 feet (ft) and subjects the vehicle to atmospheric conditions of the day. The vehicle will experience the highest dynamic pressure (Qbar) near 35,000 ft. Launch day wind speed and related atmospheric conditions will have an impact on the sensed loading which will tend to pull the trajectory away from the desired staging targets. Launch day loads and performance variations can be significant. A check of constraints and performance is required to verify that the projected flight conditions are within vehicle certification limits. Vehicle first stage steering commands and Space Shuttle Main Engines (SSME) throttle commands are updated on launch day to make the trajectory more compatible with atmospheric conditions and to rebalance the vehicle's first stage trajectory. This approach tends to reduce loads without a large impact to vehicle performance capability.

The DOLILU design process is accomplished using ground software and personnel skilled in the design and verification of the trajectory. Hours before lift-off, weather balloons are released near the launch site to measure the wind and other atmospheric conditions. Balloon data is relayed to engineers at the Johnson Space Center (JSC) to be used as in input to an iterative computer simulation program which is used to design the first stage guidance parameters or initialization loads (I-Load). A second higher fidelity six degree-of-freedom (6-DOF) computer simulation is used to validate the updates steering and throttle tables. The resulting trajectory prediction is assessed to verify that all trajectory, control, systems, structural loading, and performance constraints are met. An independent assessment of the I-loads is required prior to launch. About two hours before lift-off, the design is frozen and I-loads are uplinked to the Space Shuttle. Additional constraint verification assessments are completed using wind measurements made closer to launch. If the final constraint assessment results in a predicted constraint violation, then the launch is scrubbed and rescheduled.

\section{Team}

The console position that reports a DOLILU No-go is the Loads and DOLILU Officer (LDO). This position has the primary responsibility of the DOLILU system for a given launch. This person reports to the NASA Flight Director, Systems Integration representatives, and to the Mission Operations Directorate (MOD) representative on the NASA Mission Management Team (MMT). Reporting to the LDO are the Prime Team at JSC, the Independent Verification and Validation (IV\&V) Team, and natural environments experts at Marshall Space Flight Center (MSFC). These teams consist of subject matter experts in the fields of trajectory design, vehicle structural loadings, and vehicle performance.

The Prime Team is responsible for the trajectory design, verification, and integration of the total DOLILU system. This team operates in the Mission Control Center (MCC) at JSC. The IV\&V Team is responsible for the independent verification of the trajectory and pre-launch trajectory certification. The IV\&V Team is located at a contractor remote location. The MSFC Environments Team is responsible for wind-only DOLILU constraints and providing pre-launch environmental expertise. 


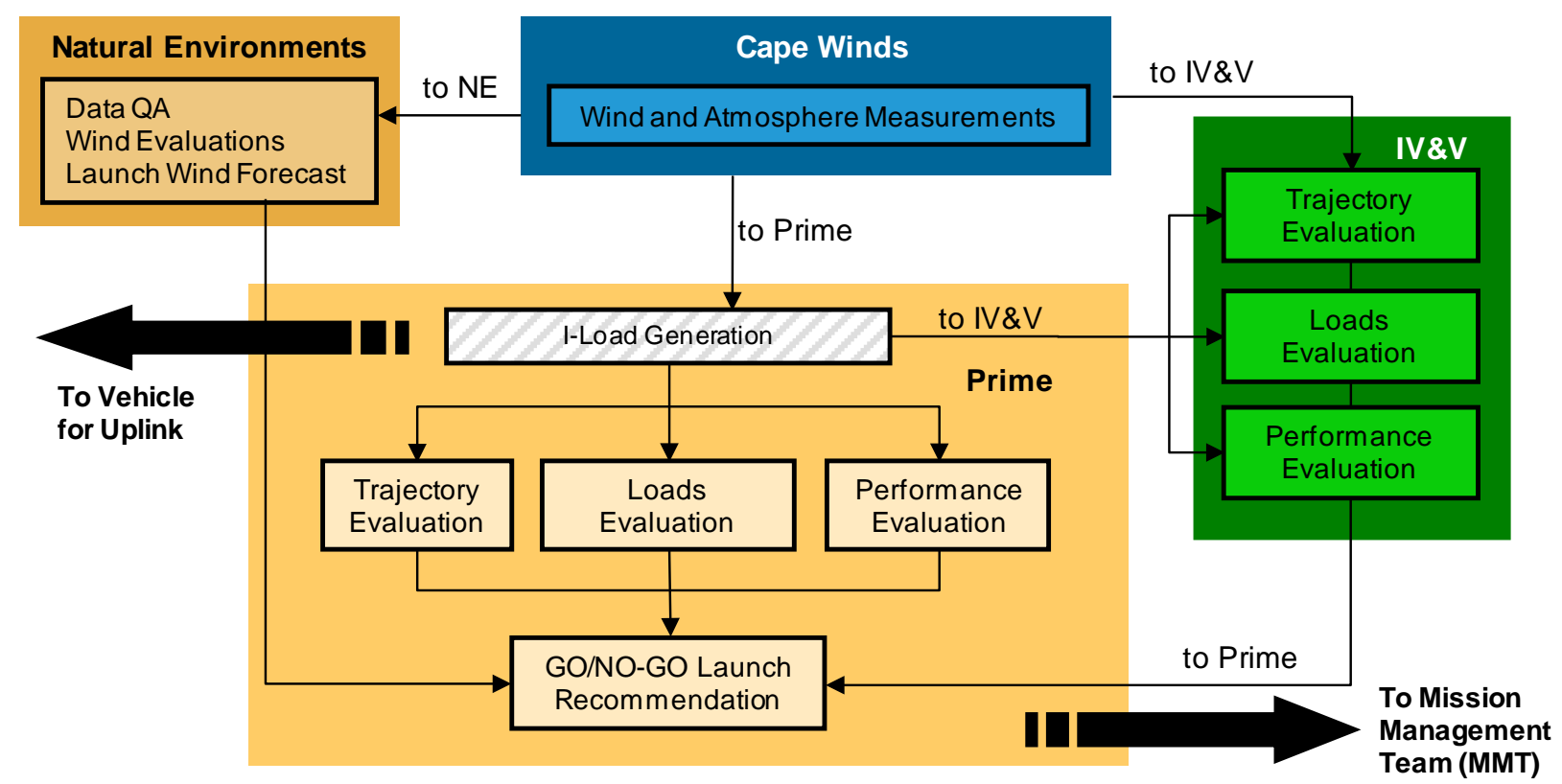

Figure 1: General Flow of DOLILU

\section{Balloon Systems}

The Space Shuttle DOLILU system requires wind speed, wind direction, and atmospheric thermodynamic data measured on the day-of-launch (DOL). This data is provided by 45th Space Wing functions at the Cape Canaveral Air Force Base (Cape), releasing weather balloons about ten miles south of the Space Shuttle launch pads. Cape personnel utilize various weather balloons and other instruments to obtain high fidelity data for Space Shuttle trajectory simulation use ${ }^{1}$.

The Radar tracked Jimsphere balloon is the baseline system to obtain high fidelity wind speed and direction up to about $58,000 \mathrm{ft}$. This weather balloon is a two meter Radar reflective sphere with 396 cones on the surface to stabilize the balloon during ascent. This balloon is tracked by one to two Radars near the Cape. The balloon takes about 65 minutes to rise to altitude with wind data reported in $100 \mathrm{ft}$ intervals. Pressure relief valves on the balloon allow it to equalize pressure and maintain a constant volume and therefore a constant rise rate of about 1000 feet per second.

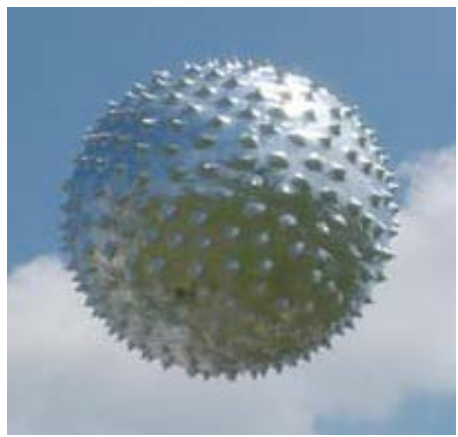

Figure 3. Jimsphere Balloon
The Automated Meteorological Profiling System (AMPS) High-Resolution balloon system measures wind speed and direction up to about 56,000 ft. Meant to replace the aging Jimsphere system, it is similar in most aspects. This balloon is not Radar tracked, rather, it has a small Global Positioning System (GPS) enabled flight element to obtain wind components. The additional weight of the flight element is responsible for the slight decrease in average altitude.

The AMPS Low-Resolution balloon system is used to measure thermodynamic data as well as wind data.

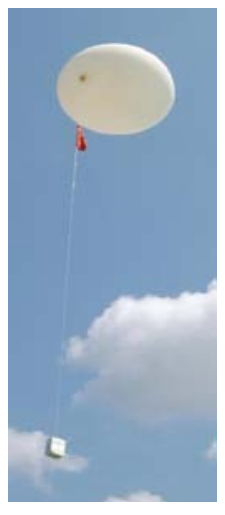

Figure 2.

Low-

Resolution

Balloon with

Flight Element 
Temperature, humidity, density, wind speed, and wind direction are reported for Space Shuttle use at $1000 \mathrm{ft}$ intervals. This balloon system utilizes a two meter latex balloon with a GPS enabled flight element hanging $70 \mathrm{ft}$ below. The Low-Resolution balloon system rises to about 100,000 ft in about 100 minutes.

The $50 \mathrm{MHz}$ Doppler Radar Wind Profiler (DRWP) is a ground Radar placed on a five acre octagon shaped field located near the launch site. Wind data is derived using Radar reflections from background particulates in the atmosphere and is measured in $476 \mathrm{ft}$ (145 meter) intervals from 8,700 ft to 61,000 ft (2.67 to 18.6 kilometers). The entire wind profile is measured every five minutes. Supplementary, $9.15 \mathrm{MHz}$ Doppler Radar Wind Profilers can be utilized to measure the wind every fifteen minutes from the surface to about $6,500 \mathrm{ft}$.

The Space Shuttle DOLILU team utilizes a forecasted wind from the surface to $80,000 \mathrm{ft}$ for wind-only evaluations. This upper level wind point forecast is created by meteorologists at JSC. Originally used for Space Shuttle entry simulation evaluations, DOLILU developed use for this wind in qualitative and quantitative real-time analysis on DOL. The forecast wind is primarily used to anticipate large changes in the wind throughout the countdown.

\section{Balloon Acceptance}

Cape personnel QA the balloon profile based on current atmospheric conditions and other atmosphere sources ensuring Space Shuttle requirements are met. Wind data is required for DOLILU evaluation from 1,500 $\mathrm{ft}$ to where the vehicle reaches mach 2.2 (on average this is $58,000 \mathrm{ft}$ ). The lower requirement of 1,500 ft is near the beginning of the Space Shuttle single axis rotation (SAR) or roll maneuver. The upper requirement of mach 2.2 corresponds to the upper limit of the structural loads and vehicle certification constraints. With the upper requirement in terms of mach, the altitude which corresponds to mach 2.2 varies, and is seasonally dependent. Mach 2.2 is higher in low performing months such as February and lower in better performing months such as October.

While the DOLILU normally only uses the Low-Resolution balloons for thermodynamic data, wind data from this balloon system can also be utilized for specific contingencies. Should neither the Jimsphere nor the HighResolution balloon reach mach 2.2, wind data from the Low-Resolution can be assessed.

Erroneous data points are removed by the Cape from the wind profiles and replaced with interpolated data. Should the Cape remove more than three consecutive data points, the profile is not acceptable for Space Shuttle evaluation. Vehicle structural load calculations are sensitive to small changes in the wind. As a result, use of data with greater than $400 \mathrm{ft}$ interpolations can result in a false Go indication.

\section{Balloon Reliability}

Not all weather balloon data is useable due to hardware, software, and operational errors. While the Radar tracking of the Jimsphere balloons topped the list of balloon problems, Jimsphere balloons are still preferred over High-Resolution balloons by the Space Shuttle Program. This preference is based on a higher termination altitude and less interpolated edits in the profile. To increase the likelihood of receiving a good profile, both balloon systems are used.

For most circumstances, a single Jimsphere balloon is tracked by two Radars. These two data streams are the prime and first backup sources for wind profile development by the Cape. Two minutes after the balloon release of the Jimsphere, a single "shadow" High-Resolution balloon is released and data is processed on two separate computers. If there is a problem with the Jimsphere data not meeting Space Shuttle requirements then the HighResolution data is utilized.

There exists a possibility of a weather balloon and Space Shuttle collision since balloons may enter the air space the Space Shuttle will occupy during flight. To enact balloon collision avoidance (COLA) mitigation, balloon groundtrack traces are plotted and compared to the Space Shuttle's groundtrack. Should there be an elevated concern, the balloon release time schedule will be modified to reduce the risk. 


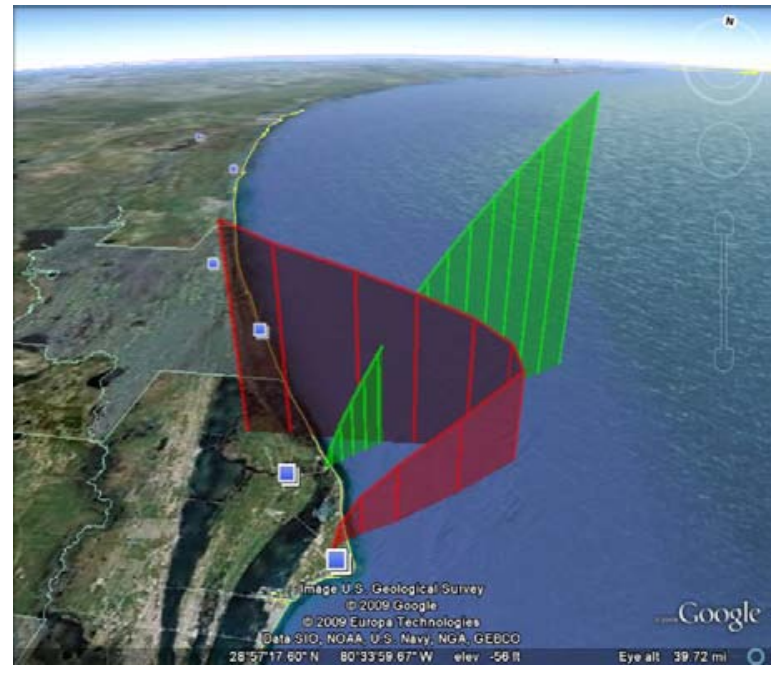

Figure 4. Balloon COLA

STS-128 on 8/24/09: L-9:00 Low-Resolution balloon (red) with Space Shuttle trajectory (green).

\section{Day-of-Launch Timeline}

The essential DOLILU process is to receive balloon data, design a trajectory, and verify that trajectory. This process is repeated throughout the launch count. The exception is that at some point, the design is frozen, but the trajectory is continually verified with up-to-date balloon data.

Low-Resolution balloons are released for atmospheric data and other customers of balloon data on DOL. All times are given in terms of Launch minus hours and minutes, or L-HH:MM. Low-Resolution balloons that DOLILU uses for atmospheric data are released at L-9:00, L-6:20, L-3:45, and L-0:30. For wind data, balloon release times are: L-6:15, L-4:50, L-3:35, L-2:20, L-1:25, L-1:08, L-0:50, and one post-flight at L+0:15. The final DOLILU Go/No-go is given by the LDO at L-0:30. While the DOLILU process is basically repeated, each balloon assessment has different purposes as Table 1 shows. 
Table 1. DOLILU Balloon Purposes

\begin{tabular}{|l|l|}
\hline $\begin{array}{c}\text { Balloon } \\
\text { Release } \\
\text { Time }\end{array}$ & \multicolumn{1}{|c|}{ Purpose } \\
\hline L-6:15 & $\begin{array}{l}\text { Balloon consists of design, High-Q verification, and roll maneuver verification. This } \\
\text { balloon is a final system check-out balloon and is the first of trending data for the day. } \\
\text { Balloon also serves as a second backup to the designed I-Loads should they have to } \\
\text { be used. }\end{array}$ \\
\hline L-4:50 & $\begin{array}{l}\text { Balloon consists of the prime design, High-Q verification, and roll maneuver } \\
\text { verification. This is the planned time to design the trajectory I-Loads. }\end{array}$ \\
\hline L-3:35 & $\begin{array}{l}\text { Balloon consists of High-Q verification and roll maneuver verification. This balloon } \\
\text { is the backup design balloon to the L-4:50 and the backup to the prime High-Q } \\
\text { verification balloon at L-2:20. The L-3:35 balloon is assessed with 3 1/2 hours of wind } \\
\text { persistence. }\end{array}$ \\
\hline L-2:20 & $\begin{array}{l}\text { Balloon consists of the prime High-Q verification. This balloon is assessed with } 2 \\
\text { hour wind persistence. }\end{array}$ \\
\hline L-1:25 & $\begin{array}{l}\text { Balloon is a contingency High-Q verification balloon. Should certain conditions } \\
\text { exist, this balloon will be the prime High-Q verification. }\end{array}$ \\
\hline L-1:08 & Balloon is the prime roll maneuver verification. \\
\hline L-0:50 & Balloon is the backup roll maneuver verification. \\
\hline L+0:15 & Balloon is used for post-flight trajectory analysis. \\
\hline
\end{tabular}

Table 2. DOLILU Balloon Schedule

L-6:15

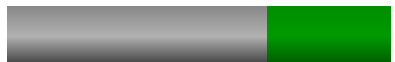

L-4:50

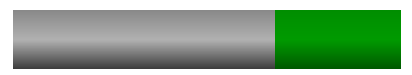

L-3:45

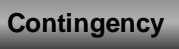

L-3:35

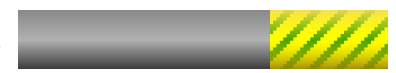

L-2:20

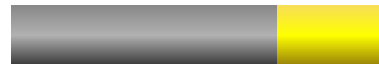

L-1:25

Contingency

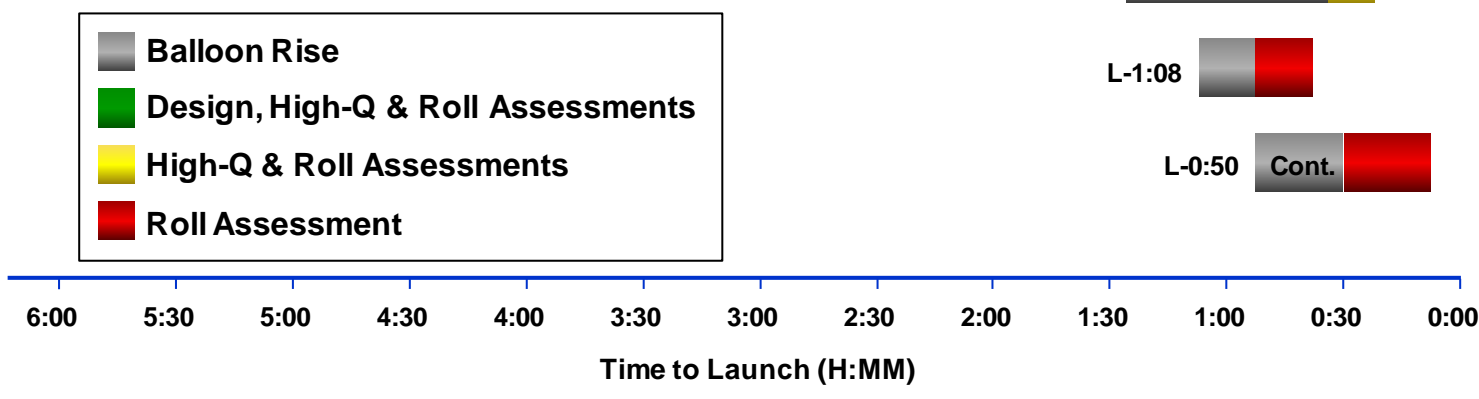




\section{Trajectory Design}

DOLILU designs the pitch, yaw, and throttle commands for the Space Shuttle. The DOLILU design targets an optimal angle-of-attack (Alpha) schedule to negative four degrees which reduces wing loading during ascent, targets angle-of-sideslip (Beta) to zero degrees to reduce side loads, and recalculates the throttle command to keep the maximum dynamic pressure (Qbar) near a design target. Since potential wind variations are greater in the winter than in the summer, the Qbar target is reduced for a winter launch. Angle-of-attack and sideslip targets are not updated for a winter launch. DOLILU rebalances the steering and throttle command tables through two steps.

The first step uses an iterative three degree-of-freedom computer simulation that results in a first cut at the pitch and yaw I-Loads and the final throttle commands tables. The SSMEs throttle down to reduce Qbar and structural loads and throttle back up after passing through the point of peak dynamic pressure. The wind profile used for this first step is filtered, or smoothed, using a four pass Martin-Graham low pass filter. This, approximately 15,000 ft filter, removes wind features which are not considered to be persistent between the design wind measurement and the actual launch.

The first pass also determines the on-board wind table. This is an eight point table represented by north and east components of the wind. The wind points from the surface to 70,000 ft are used to approximate the wind velocity and therefore mach. Given this knowledge of the wind onboard, certain vehicle I-Loads were standardized such as the Space Shuttle elevon schedule that is used to reduce elevon hinge moment loading during flight.

The second step uses a higher fidelity simulation program that includes 6-DOF effects. This simulation utilizes the unfiltered measured wind to fine-tune the pitch and yaw I-Loads by centering the trajectory on the induced Alpha and Beta spikes. The resultant pitch and yaw I-Load tables are referenced to thirty specific velocities.

The designed trajectory is optimized for a specific wind, but has been demonstrated to be valid for the actual launch wind. In operations, the nominal design balloon is released at L-4:50, with the first backup at L-3:35, and the second backup at L-6:15. The I-Load balloon is chosen based on visual comparison from the L-4:50 balloon to the forecast balloon. Should a large amount of change be observed or predicted, the timeline will support a delay the design of I-loads until the L-3:35 balloon. The updated I-Load tables are uplinked to the Orbiter on the launch pad at roughly ninety minutes before launch. Constraint assessments are required to made using later balloon measurement in order to account for wind changes which may adversely impact vehicle constraints.

\section{Structural Load Indicator Constraints}

The integrated Space Shuttle vehicle is made up of one External Tank (ET), two Solid Rocket Boosters (SRB), and the Space Shuttle Orbiter itself. Airloads and throttle-sensitive structural loads certification constraints are evaluated on DOL to verify that the predicted trajectory is within certification. Given the short time to assess constraints and the risk with complex algorithms, simplified structural load indicators (SLI) were developed from higher fidelity structural analytical limits to determine element structural loadings given a newly designed trajectory on DOL. Forty-two SLI protect specific points on the integrated vehicle such as Shuttle to ET attach loads.

SLI are evaluated in the High-Q region of flight which is defined from mach 0.6 to 2.2. This region will contain the ramp up to the maximum Qbar in flight and then the beginning of the ramp down. Trajectory data is fed to a post-processor to determine the defined SLI for evaluation. The limit for each SLI is different and can vary across the evaluated mach region. Each SLI load from the post-processor is then further dispersed closer to the ultimate limit with unmeasured effects. Wind persistence, system dispersions, and gust dispersions are combined using a root sum squared method. This total dispersion is then added to the undispersed value, and compared to the limit. The difference is margin. If the minimum margin over the mach region is positive, then the SLI is Go. Should the margin be negative, the SLI is No-go. If the last balloon assessment for the SLI is No-go, then DOLILU will be Nogo for that launch attempt. 


\section{Q-Plane Constraints}

Integrated vehicle airloads certification limits are protected by evaluating a simplified constraint that compares the predicated trajectory's resultant Alpha, Beta, Qbar, at varying Mach numbers to a pre-verified "Q-plane” or "Squatchaloid" constraint. This four dimensional space uses Mach as the independent variable, where there exists a three dimensional space with Alpha and Beta on the horizontal plane and Qbar in the vertical. Therefore, at a Mach, there can exist a frustum or cylinder shaped limit. With this limit, Qbar can be traded for Alpha and Beta. That is, the vehicle can withstand larger Alpha and Beta variation from the optimal if the vehicle experiences a lower Qbar. Figure 5 shows a Q-plane at a given Mach and Qbar. For every Mach, if the Alpha, Beta, Qbar point is determined to be inside the frustum, then the constraint is Go.

Elements of the Space Shuttle integrated vehicle are then able to define a safe region of flight that is simple to evaluate on DOL. Four separate Q-Plane constraints are assessed on launch day. Each protects a specific certification limit or operational constraint.

- The Orbiter Q-planes protect the orbiter structural load redlines.

- The ET Protuberance Zero Margin Squatchaloid protects External Tank structural limits which are primarily driven by ET protuberances.

- The Performance Enhancement DOLILU II Verification Space protects certification limits assessed during validation of the DOLILU process. The boundary conditions which this limit protects were evaluated and cleared during certification of the DOLILU process.

- The Roll Maneuver Q-plane protects the integrated vehicle during the roll maneuver to the flight heading which is initiated after the Shuttle clears the launch tower. This limit was put in place after the loss of Columbia. In the detailed reconstruction of this mishap, it was discovered that the certified SRB aft strut loads were almost exceeded during this maneuver. Certification loads in this region were derived from flight experience and analysis. A Q-Plane constraint was derived which was intended to verify that the day-of-launch prediction was within certification in the region from Mach 0.25 to 0.5.

For each of the Q-planes, similar to the SLI, there is a statistical dispersion for unmeasured effects. Wind persistence, system dispersions, atmosphere persistence, gust, and engine-out effects are accounted for in the assessment of the Q-planes. Wind persistence, system dispersions, and atmosphere persistence are root-sumsquared. This dispersion is then added to the measured trajectory data. The limits themselves are reduced for the engine-out and gust effects. Should the margin from the dispersed trajectory point to the reduced limit be positive, then the constraint is Go, otherwise No-go.

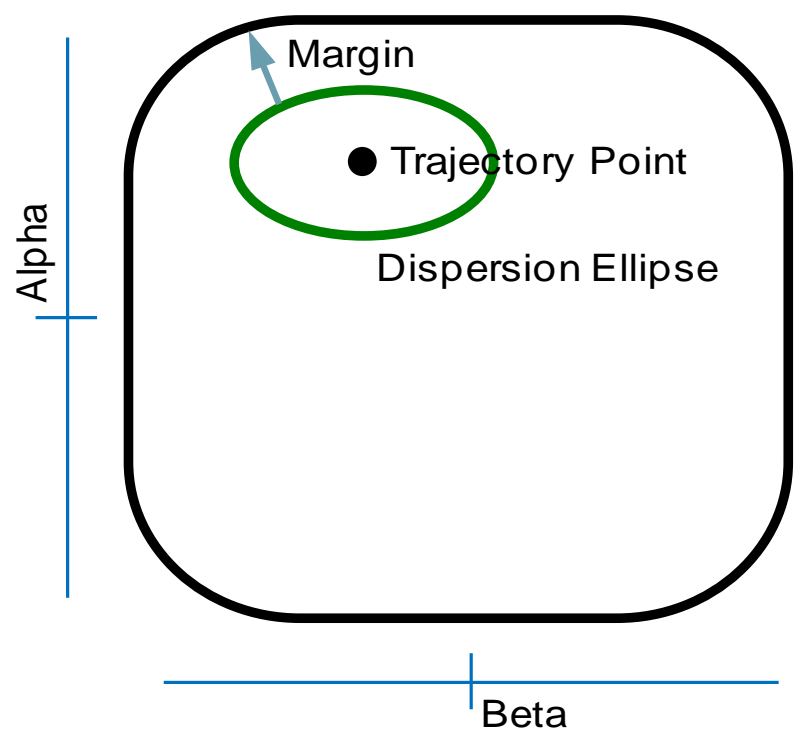

Figure 5. Example Q-Plane 


\section{Trajectory Parameter Constraints}

DOLILU certification constraints are assessed by verifying that the launch day prediction is within the DOLILU trajectory certification envelope. These rules are grouped into sub-classes based on their developmental heritage and their criticality. "Experience" or "E" rules represent the limit of certification and not necessarily the limit of capability. E Rules include: attitude errors, angular accelerations, SSME and SRB thrust vector steering commanded positions, Orbiter elevon hinge moments, the pitch and yaw steering tables, and the updated on-board wind table. Each parameter is compared to the experience database used in vehicle certification of the expected envelope of trajectories and the minimum is reported. Should this minimum be negative, then the rule is broken. If there is good rationale to explain why it is safe to fly, then an "Exception" to the E rule can be enacted with proper approval.

"System" rules, also called "S" rules, are hard constraints used to verify the vehicle's staging limits, vehicle pitch/yaw/roll rates, Range Safety limits, and throttle limits. These rules are quantified in the same manner as the $\mathrm{E}$ Rules. "Processor Integrity" or "P" rules are similar to S Rules and used to ensure computer simulations compare well and converge to solutions. S rules and $\mathrm{P}$ rules require a higher level of approval should the rule have good rationale to "Waive" the rule. All trajectory rules have been reduced to account for wind persistence and system dispersions on the evaluated rule.

\section{Wind Persistence Dispersion}

The DOLILU system will give the final trajectory assessment based on balloon data released 2 hours and 20 minutes before launch. This is the final Go/No-go placard due to the 65 minute balloon rise, computer processing time, quality assurance, and reporting time. Therefore, the final DOLILU assessment does not truly assess the real wind that the Space Shuttle will experience. The wind from the surface to $60,000 \mathrm{ft}$ will continue to change through the launch time and the impact on any actual constraint may not be completely understood without a full assessment. "Wind persistence" is the term given to define this lack of temporal persistence on the vehicle constraints due to the changing wind.

Both the SLI and Q-plane constraints utilize a "Minimum Margin” statistical method ${ }^{2}$. Margin is defined as the distance from a parameter to its limit. Minimum margin then represents the closest margin over a range of values. Should the parameter exceed the limit, the minimum margin would then represent the largest violation of the limit. This methodology offers the advantages of protecting the actual limits and is insensitive to wind features shifting in altitude. Minimum margin determines the protection required for a parameter to not exceed the constraint $99 \%$ of the time at any point in the evaluated region.

To develop the wind persistence dispersion, the Space Shuttle Program utilized a database of measured wind profiles released from the launch site at fixed intervals. Wind profiles measured both about 2 and $3 \frac{1 / 2}{2}$ hours apart were cataloged and totaled 1000 wind profile pairs. Seasonal differences exist in upper atmospheric winds, therefore, the database is further split into seasons and analyzed independently. For the first of the wind pair, a trajectory design was generated, the trajectory was flown, and the Q-plane's Alpha, Beta minimum margin was determined. For the second of the pair, the design was from the first wind was flown through using the second wind and the Q-Plane Alpha, Beta Minimum Margin was determined.

Using this minimum margin data, the mean and standard deviation of the first of the pairs and of the second of the pairs can be computed. Additionally, the correlation coefficient between each can be computed. This data will be used in a bivariate conditional Gumbel probability distribution.

Only two dispersion increments were developed: 2 hour and 31/2 hour. Therefore, inside of 2 hours to launch, the 2 hour increment is utilized. Should the contingent L-1:25 hour assessment be required, the result might be slightly conservative. However, closer to launch, there exist other means to protect the DOLILU design with wind-only assessments. 


\section{Wind-Only Assessments}

DOLILU consists of the Prime Team at JSC, the IV\&V Team at a contractor facility, and the MSFC Environments Team who specialize in meteorological data and were responsible for several DOL critical functions listed below ${ }^{3}$.

- Wind profile reasonableness qualitative assessment of the Cape's wind profile is completed by comparison to other measurement systems.

- Wind shear quantitative assessment measures each wind profile maximum out-of-plane wind shear at various altitude intervals. This check ensures that the DOL wind's shear was inside of vehicle certification of the vertical tail.

- Large scale wind change qualitative assessment is an intentionally vague rule to stop a launch should upper level wind conditions substantially change such that the DOLILU assessment no longer is valid. In practice, this rule was never enacted for any Space Shuttle launch.

- Wind change redline ${ }^{4}$ quantitative assessment is a rule to complete a conservative approximation to a true trajectory assessment. This rule was developed after the Columbia accident. Primarily used from one hour to 15 minutes of launch, this rule is best used when there is not enough time to complete trajectory assessment of a balloon. This rule differences the filtered design wind to a current filtered wind - often a $50 \mathrm{MHz}$ DRWP wind profile. This delta is then compared to a redline. Should the difference exceed the redline for an amount greater than the tolerance, the Space Shuttle would be considered No-go.

\section{Independent Verification and Validation}

While the Prime Team designs and verifies the design, the IV\&V Team specializes in verification. For the Space Shuttle Program, the IV\&V Team is contracted under the development contractor who maintains independence by a separate management chain and separate facilities. This team not only participates in DOL assessments, but is heavily involved in every DOLILU process decision through a common long-standing working group. The IV\&V organization is assigned to the NASA Systems Integration and Engineering organization while the Prime Team is operated by the NASA Mission Operations Directorate. This difference at many levels affords good autonomy with good collaboration between systems integration and operations organizations.

Between the IV\&V and Prime Teams, software tools are independently coded to the same requirements. Software configuration management and internal procedures are implemented differently, but designed to the same standards. This independence is continued to launch day, where the IV\&V Team independently receives the wind profile data from the Cape. In order for DOLILU to be Go, constraint margins between the Prime and IV\&V Teams must compare to within defined tolerances.

\section{Vehicle Certification and Launch Probability}

Significant prelaunch work by the Prime and IV\&V organizations is done to certify the DOLILU system for flight. While DOLILU reduces the trajectory variation given different atmospheric conditions, the expected variation is important to certify the vehicle's flight envelope. A large set of trajectories is routinely run to offer subsystems a trajectory baseline for certification and impact changes to the DOLILU process or constraints. This process is termed, launch probability.

Launch probability is a quasi-Monte Carlo process where various winds and atmospheric data are entered into the DOLILU design and assessment process to report a Go percentage. A database of 150 measured Jimsphere balloons for each month is combined with monthly measured atmosphere data. DOLILU then uses each wind and 
atmosphere for design and constraint assessment. This results in $150 \mathrm{Go}$ or No-go placards. Thus, the percent Go is probability of launch.

Baseline DOLILU launch probability demonstrates a minimum of $90 \%$ in February, and near $100 \%$ for July. When considering a change to the DOLILU process, design or inputs, the impact to launch probability is quantified. For example, should the wind persistence dispersion need to increase, the resultant launch probability can be delivered to show the impact.

DOLILU has significantly improved launch probability over other design methodologies. If DOLILU did not exist, and a mean wind design was utilized for the Space Shuttle, the launch probability for February would be reduced from about $90 \%$ to about $30 \%$. This is the effectiveness of DOLILU. DOLILU re-centers and reduces the vehicle loads, while normalizing ascent performance.

\section{Ascent Performance Margin}

The Space Shuttle aims to have more propellant at MECO than is required, thus reducing the risk of not meeting mission objectives. Excess propellant at MECO is termed performance margin and is calculated in terms of pound mass. This performance could have been used to bring more payload to orbit.

Flight Performance Reserve (FPR) is a statistical dispersion for in-flight performance deviations added to the required amount of propellant to ensure a guided MECO. Ascent Performance Margin (APM) is performance above FPR and above other unusable propellants remaining at MECO. APM is managed pre-launch for manifesting purposes and on day of launch for launch window length determination.

Flight Performance Reserve is developed to compensate for higher than nominal propellant consumption. These approximately $3000 \mathrm{lbs}$ represented a three-sigma likelihood that the vehicle will not run out of Liquid Oxygen (LOX) or Liquid Hydrogen (LH2). Due to the engine mixture ratios, it is beneficial to bias the LH2 heavy. This "fuel bias" is approximately 1000 lbs.

In the months and years before each flight, the Space Shuttle Program needs to understand the variation of APM. APM is used to cover the impacts of the variations in SRB propellant temperatures, variations in SRB burn rates, monthly variations in wind and atmosphere, monthly variation in performance, variations in DOL propellant loading, expected variations in vehicle element weights including payload throughout the mission planning timeframe, and a desired launch window length.

Average APM varies throughout the year and is primarily influenced by SRB propellant mean bulk temperature (PMBT) and average atmospheric conditions for each month. Average monthly wind, atmosphere, and PMBT combine to vary APM by 1000 lbs from a low in February to the best performing month of October.

In addition to the monthly variation in APM, certain effects are not known until launch day. The Space Shuttle Program seeks to maintain a total of $900 \mathrm{lbs}$ of vehicle performance for these uncertainties: actual DOL wind and atmosphere, launch minus three day PMBT changes, and actual Liquid Oxygen (LOX) and Liquid Hydrogen (LH2) loading.

This propellant load is calculated on DOL using estimated LOX and LH2 density derived from measured LOX and LH2 ullage pressures. The LH2 actual propellant load is fairly constant, however the LOX load densifies over time. While maintaining the LOX liquid level for approximately six hours and 30 minutes, the LOX mass tends to effectively increase by $0.3 \%$ of the total load.

The Space Shuttle Program plans a five minute launch window for International Space Station (ISS) missions. This is centered at an in-plane launch and two minutes 30 seconds on either side. An in-plane launch time has the most APM where the vehicle does not have to complete out-of-plane steering. The APM cost to allow a five minute window is about $600 \mathrm{lbs}$. 
The performance dispersions can be totaled:

$$
\text { FPR (3000) + Fuel Bias (1000) + DOL Dispersions (900) + Launch Window (600) = } 5500 \mathrm{lbs}
$$

The Space Shuttle is reasonably assured of launching with positive APM and not running out of performance before MECO. With the APM variation given launch day conditions, accurate launch times are communicated to others in Mission Control responsible for close-to-launch holds.

\section{DOLILU Uplink}

Following a validated DOLILU design, the I-Loads are uplinked to the Space Shuttle vehicle. The Prime Team at JSC is responsible for delivering the I-Loads to the MCC's Guidance Procedure Officer (GPO). These I-Loads are combined with other recently modified I-Loads for both the nominal mission and aborts from a delivery at launch minus 15 days. This combined package is uplinked to the vehicle. Data integrity is verified by dumping the actual Space Shuttle General Purpose Computer's (GPC) memory. This memory dump is then down linked and compared, by the GPOs, to the original I-Loads. The entire uplink process and quality assurance takes about 30 minutes. The DOLILU IV\&V Team does not receive a down link of the I-Loads.

This uplink must be accomplished in a vehicle computer mode capable of receiving such data which ends at about launch minus one hour. The DOLILU process is configured to only uplink one set of I-Loads per launch attempt, and does not support the substitution of later "better" I-Loads. The DOLILU uplink is one of only a handful of critical prelaunch uplinks of key GNC parameters on the day-of-launch.

\section{Conclusion}

The DOLILU process is critical to the safety of the vehicle. The Space Shuttle DOLILU system represents a well evolved method which may be used as a template for future launch vehicle systems. The Space Shuttle's Dayof-Launch Initialization Load Update system is successful in achieving the goals of maintaining safety, reducing vehicle structural loads, and improving launch availability.

\section{Acknowledgments}

The authors would like to thank all those involved in the last years of Space Shuttle DOLILU operations, especially: Paul Thomas, Michael Harvey, Daniel Puperi, Michael Scott, Paul Duffin, Angela Lenort, Carl Merry, Chauncey Williams, Bridget Knight, and Jennifer Weinstein.

\section{Nomenclature}

$\begin{array}{ll}\text { 6-DOF } & =\text { Six Degree-Of-Freedom } \\ \text { Alpha } & =\text { Angle-of-Attack } \\ \text { AMPS } & =\text { Automated Meteorological Profiling System } \\ \text { APM } & =\text { Ascent Performance Margin } \\ \text { Beta } & =\text { Angle-of-Sideslip } \\ \text { Cape } & =\text { Cape Canaveral Air Force Base } \\ \text { COLA } & =\text { Collision Avoidance } \\ \text { DOL } & =\text { Day-Of-Launch } \\ \text { DOLILU } & =\text { Day-of-Launch Initialization Load Update } \\ \text { DRWP } & =50 \text { MHz Doppler Radar Wind Profiler } \\ \text { ET } & =\text { External Tank }\end{array}$




\begin{tabular}{|c|c|c|}
\hline $\mathrm{ft}$ & $=$ & Feet \\
\hline FPR & $=$ & Flight Performance Reserve \\
\hline GPC & $=$ & General Purpose Computer \\
\hline GPO & $=$ & Guidance Procedure Officer \\
\hline GPS & $=$ & Global Positioning System \\
\hline I-Load & $=$ & Initialization Load \\
\hline ISS & $=$ & International Space Station \\
\hline IV\&V & $=$ & Independent Verification and Validation \\
\hline JSC & $=$ & Johnson Space Center \\
\hline LDO & $=$ & Loads and DOLILU Officer \\
\hline LH2 & $=$ & Liquid Hydrogen \\
\hline LOX & $=$ & Liquid Oxygen \\
\hline MCC & $=$ & Mission Control Center \\
\hline MECO & $=$ & Main Engine Cut-Off \\
\hline MMT & $=$ & Mission Management Team \\
\hline MOD & $=$ & Mission Operations Directorate \\
\hline MSFC & $=$ & Marshall Space Flight Center \\
\hline NASA & $=$ & National Aeronautics Space Administration \\
\hline PMBT & $=$ & [SRB] Propellant Mean Bulk Temperature \\
\hline QA & $=$ & Quality Assurance \\
\hline Qbar & $=$ & Dynamic Pressure \\
\hline SAR & $=$ & Single Axis Rotation \\
\hline SLI & $=$ & Structural Load Indicator \\
\hline SRB & $=$ & Solid Rocket Booster \\
\hline SSME & $=$ & Space Shuttle Main Engines \\
\hline
\end{tabular}

\section{Reference}

${ }^{1}$ Bellue, D. G., Boyd, B. F., Vaughan, W. W., Madura, J. T., Garner, T., Winters, K. A., Weems, J. W., Herring, H. C., "Shuttle Weather Support from Design to Launch to Return to Flight", $12^{\text {th }}$ Conference on Aviation Range and Aerospace Meteorology, CP8.1, AMS, Atlanta, GA, 2006.

${ }^{2}$ Smith, O. E., Adelfang, S. I., "A Compendium of Wind Statistics and Models for the NASA Space Shuttle and Other Aerospace Vehicle Programs,” NASA/Cr-1998-208859, 1998

${ }^{3}$ Decker, R. K., and Leach, R. "Assessment of Atmospheric Winds Aloft during NASA Space Shuttle Program Day-ofLaunch Operations,” AIAA Aerospace Sciences Meeting and Exhibit, CP266, AIAA, Reno, NV, 2005.

${ }^{4}$ Decker, R. K., Puperi, D., Leach, R. "Impact to Space Shuttle Vehicle Trajectory on Day of Launch from change in Low Frequency Winds,” AIAA Aerospace Science Meeting-Atmospheric and Space Environments, CP1100, AIAA, Reno, NV, 2007.

"Norbraten, L., "Day-of-Launch I-Load Updates for the Space Shuttle," AIAA Space Programs and Technologies Conference, CP1274, AIAA, Huntsville, AL, 1992.

"Johnson, D. L., “Terrestrial Environment (Climatic) Criteria Handbook for use in Aerospace Vehicle Development,” NASAHDBK-1001, 2000. 


\section{Space Shutt]e Day-of-Launch Trajectory Deslghj Operations}

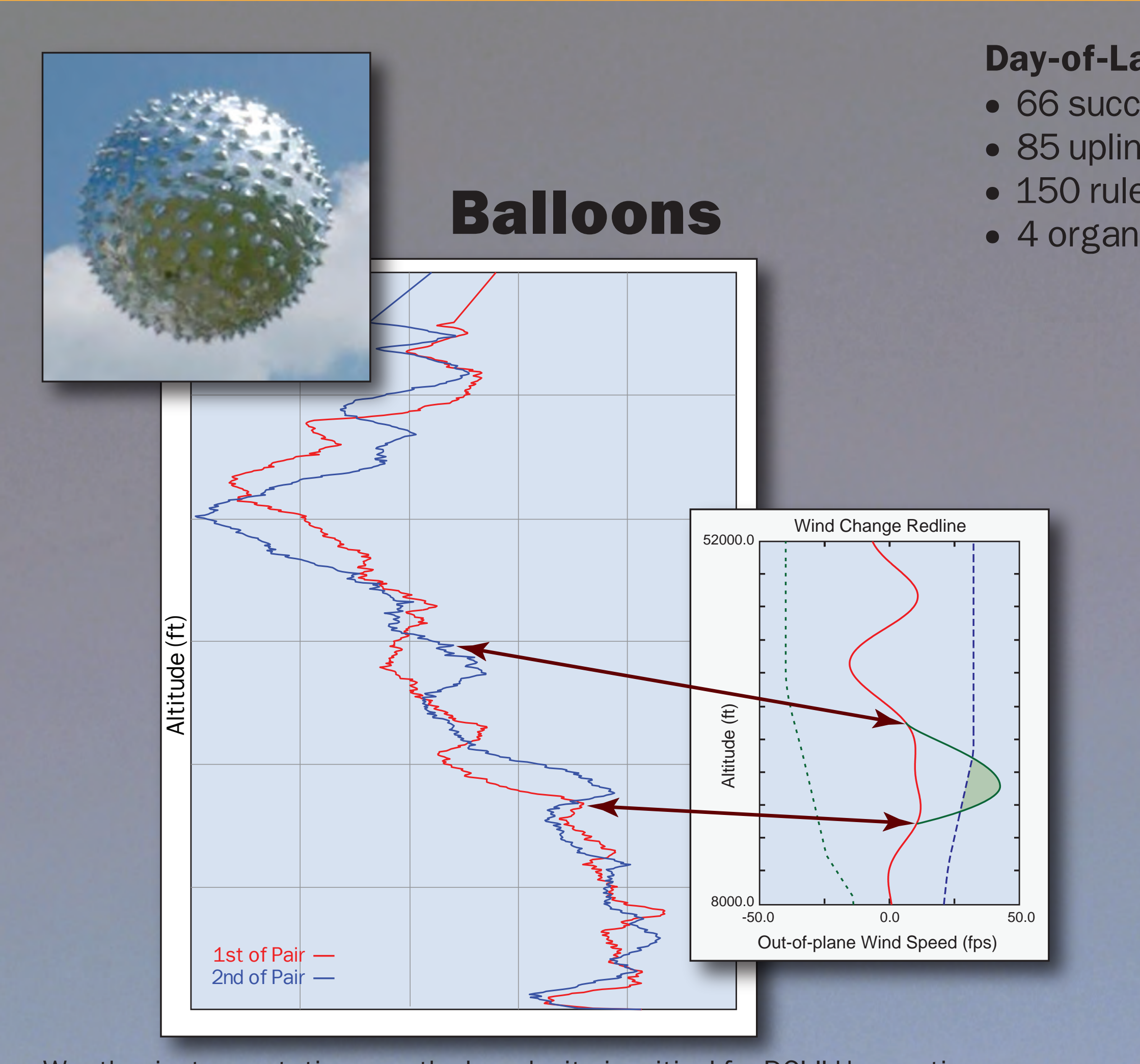

86 uplinked parameters designed on launch day
.

- 4 organizations working in concert

- limsphere Radar tracken nar the launch site is critical for Dolitu operations.

: thermodynamic data
: UpHA Dopoler Radar Wind Profiler (DRWP) measures wind data
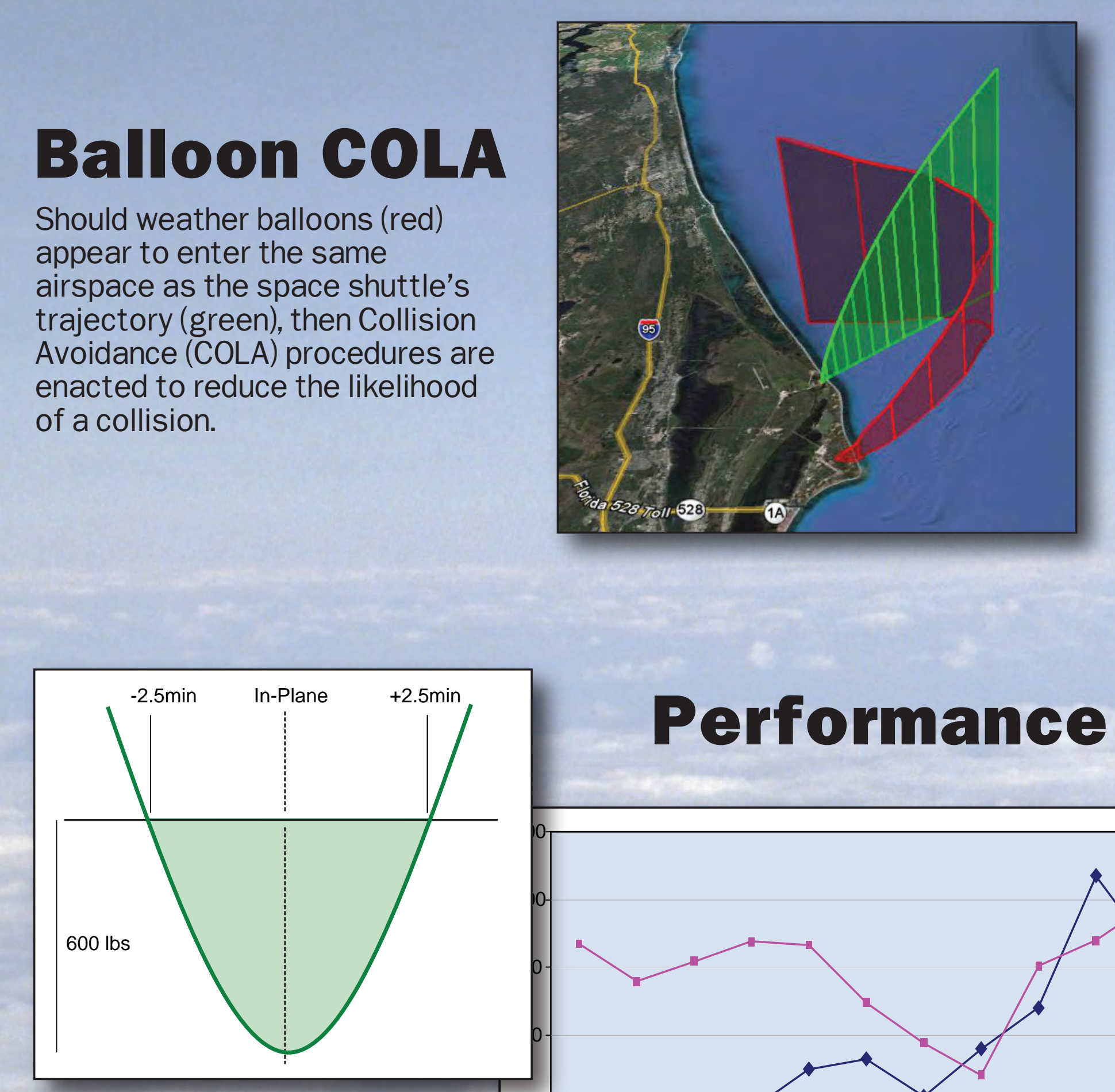

\section{Performance}

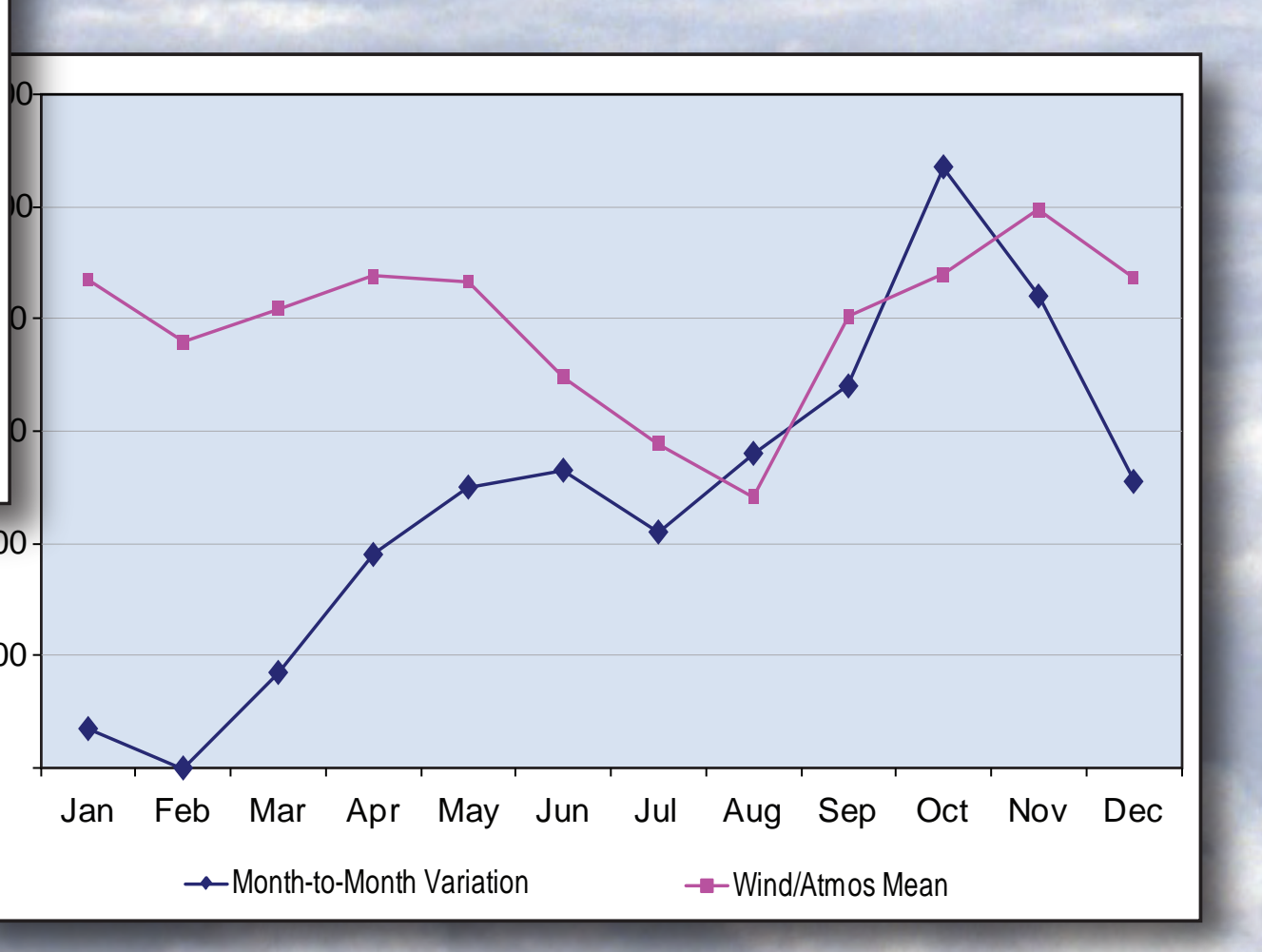

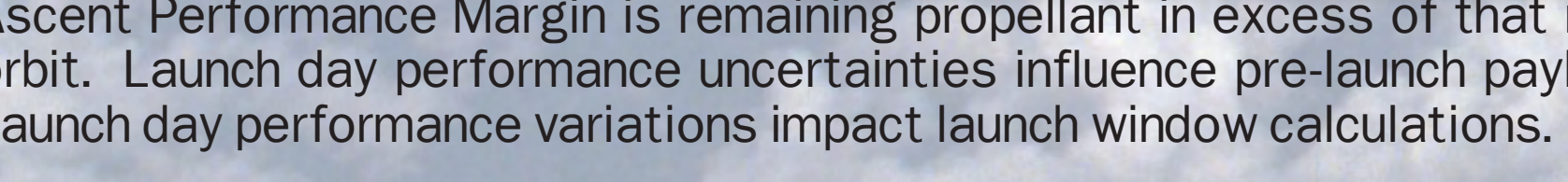

DOLILU is the process by which the space shuttle's

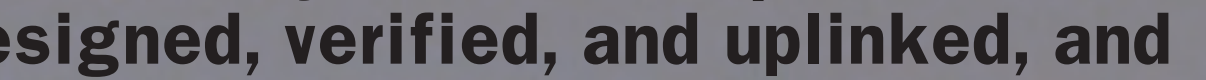
which does the following:

Maintains safety of crew and vehicle

- Reduces vehicle loads

Balloon Schedule

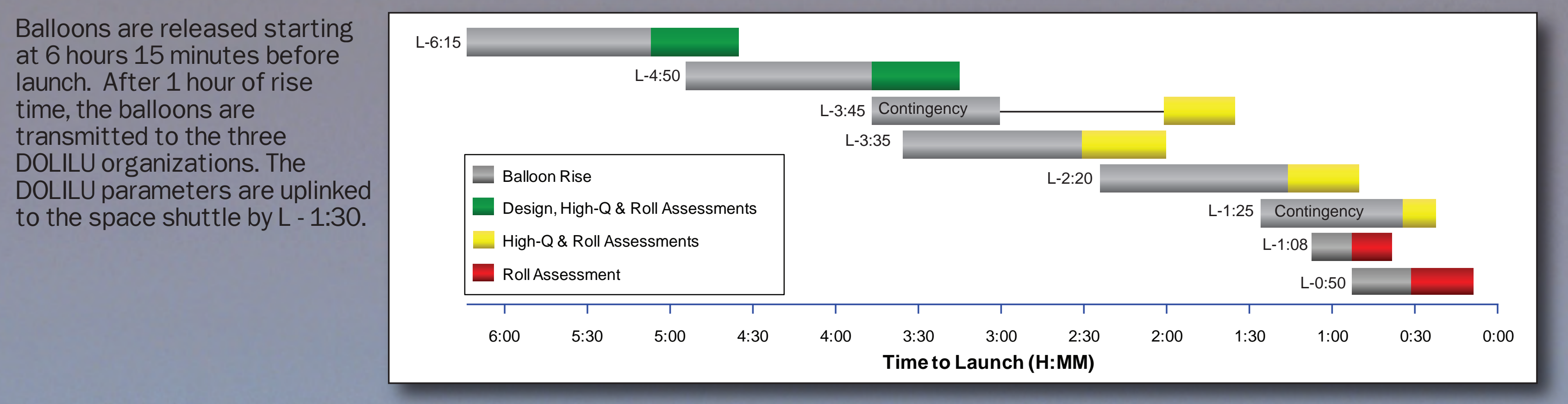

DOLILU Overview

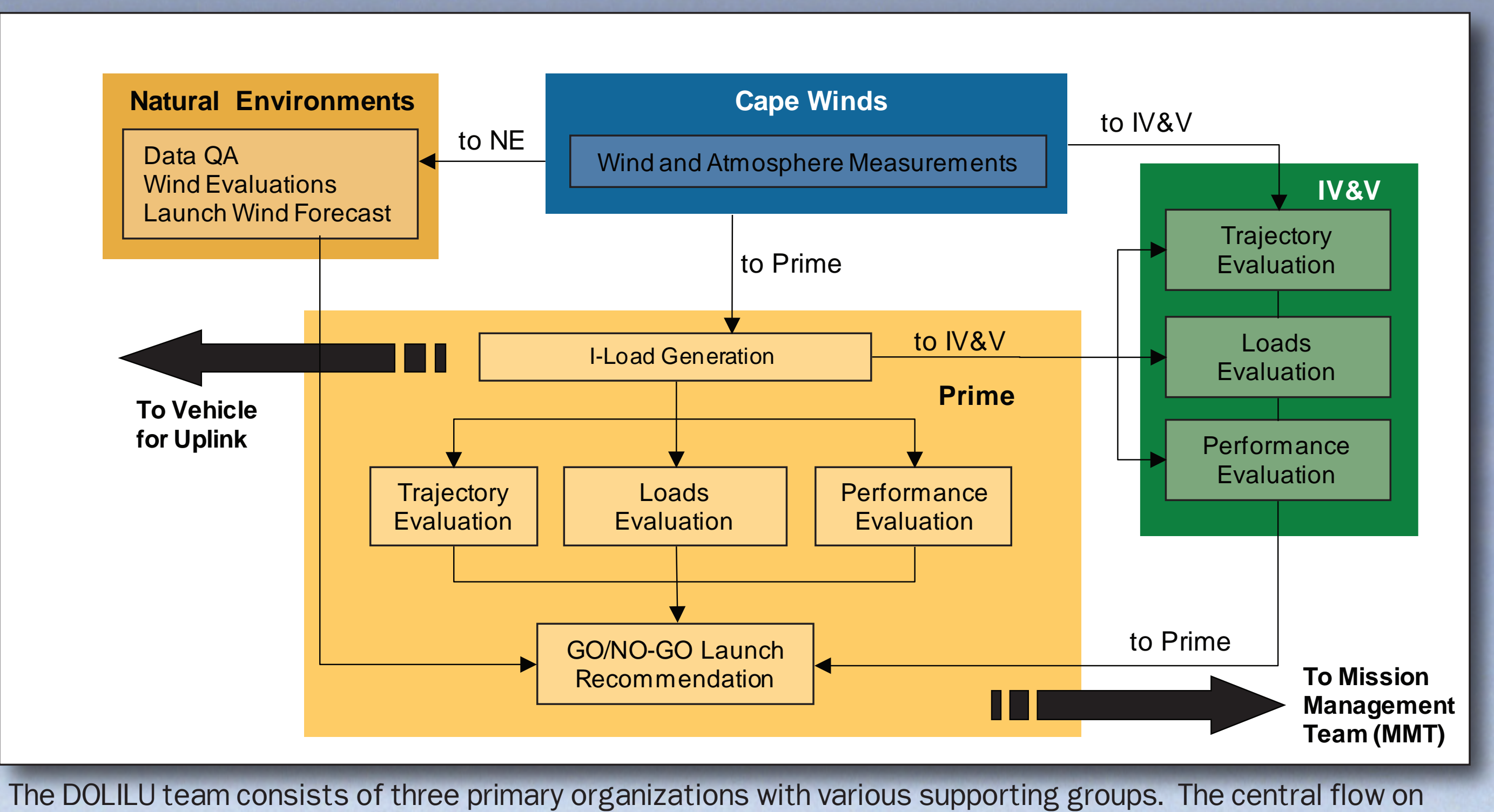

The DOLLUU team consists of three primary organizations with various supporting groups. The central flow on
day-of-launch is for wind datat to flow from the Cape to the Prime Team at Johnson Space Center, to the Independent Verification and Validation (IV\&V) Team at a contractor-managed remote location, and to natural
environments experts at Marshall Space Flight Center (MSFC). The Loads and DOLLU Officer (LDO) on the Prime

Launch Probability

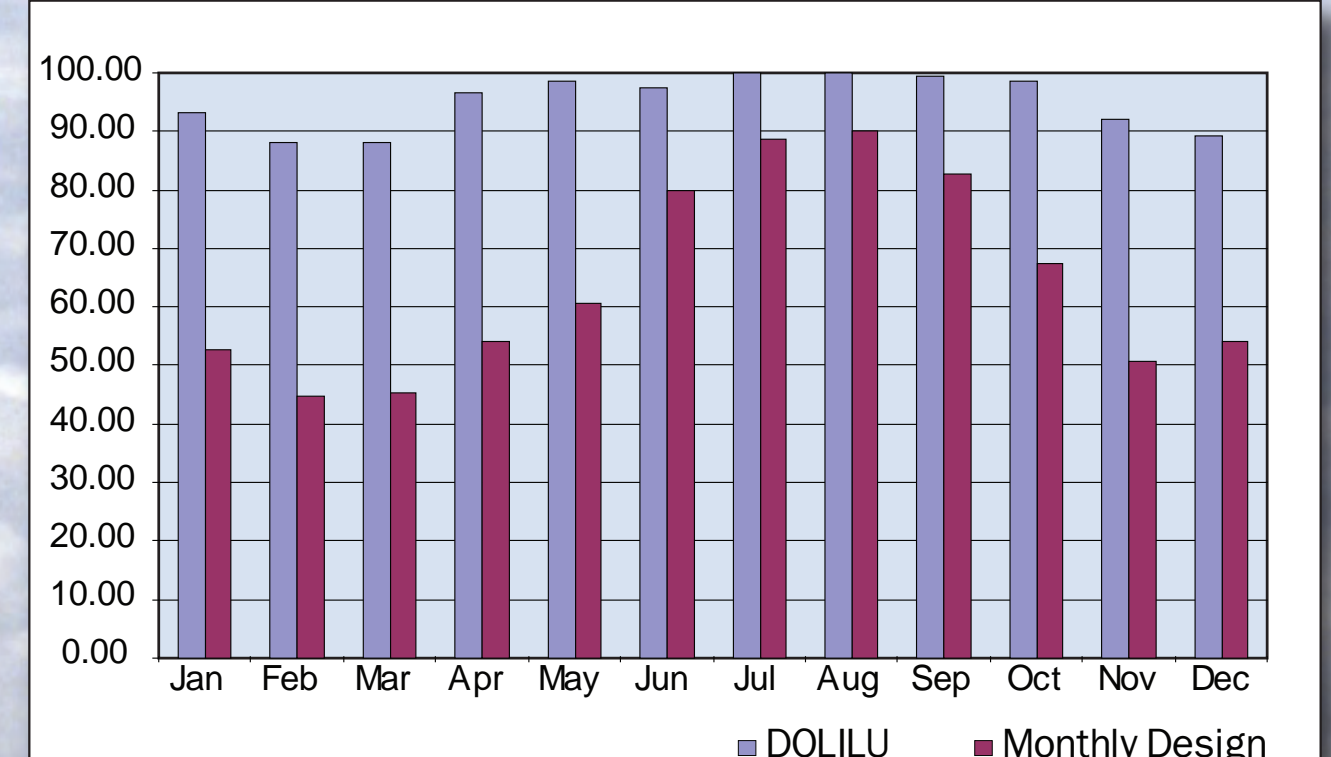

Wind Persistence

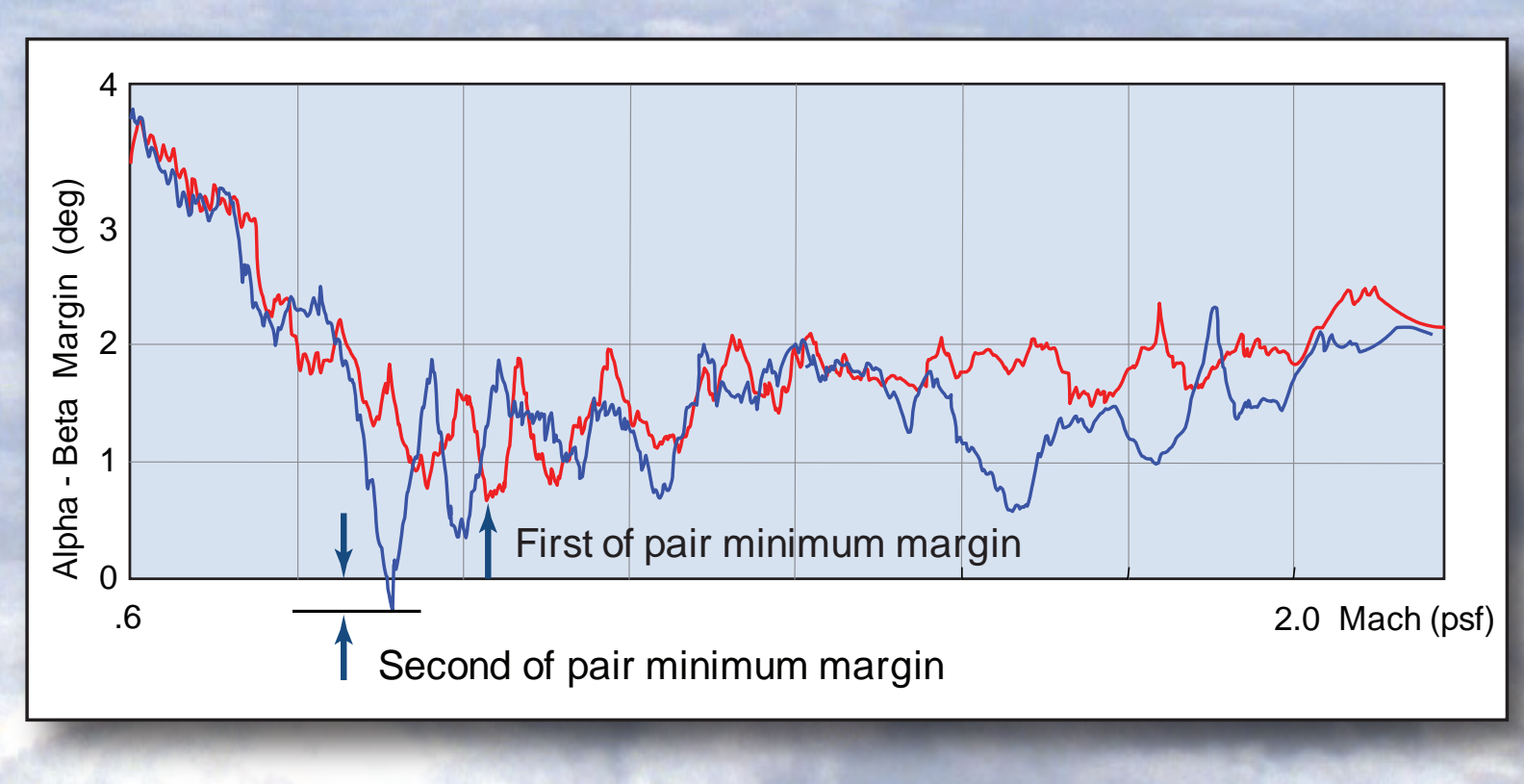
Because the wind will continue to change after the last
assessment at $L-2: 20$ to launch time, a generic dispersion acent for the resultant change in constraint margin. The wind persistence dispersion is developed in a manner imitating the
launch day process. Wind $A$ is designed and assessed, followe
I-Load Design For the Initialization Load Design, DoLILU targets an optimal alpha of - $4^{\circ}$ to protect wing loads, and a Beta
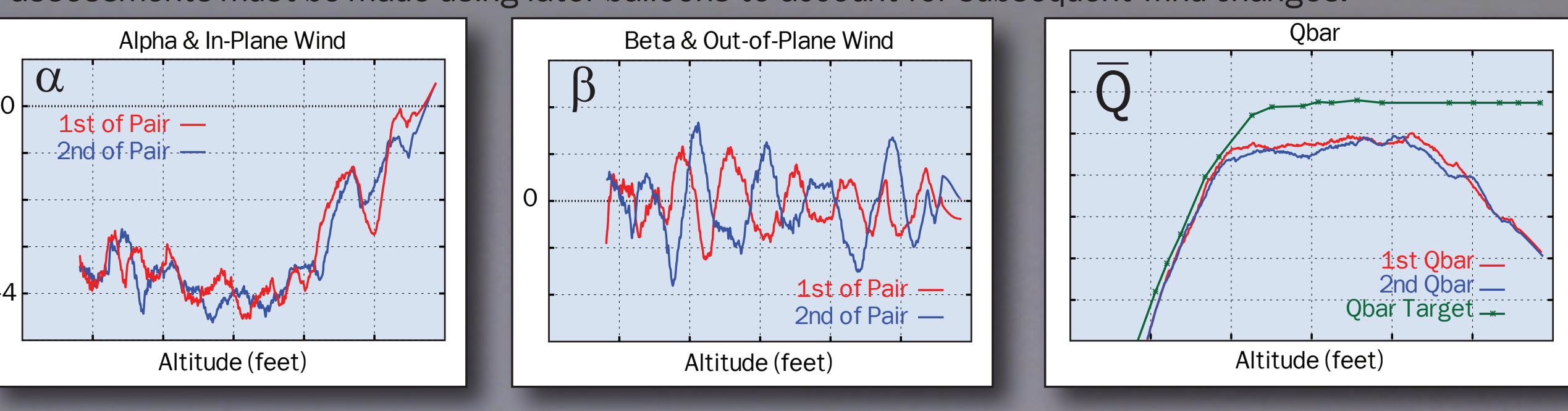

Planes

- Trajectory Parameter Rules

- Wind-only

- Compares from Prime to IV\&V Teams
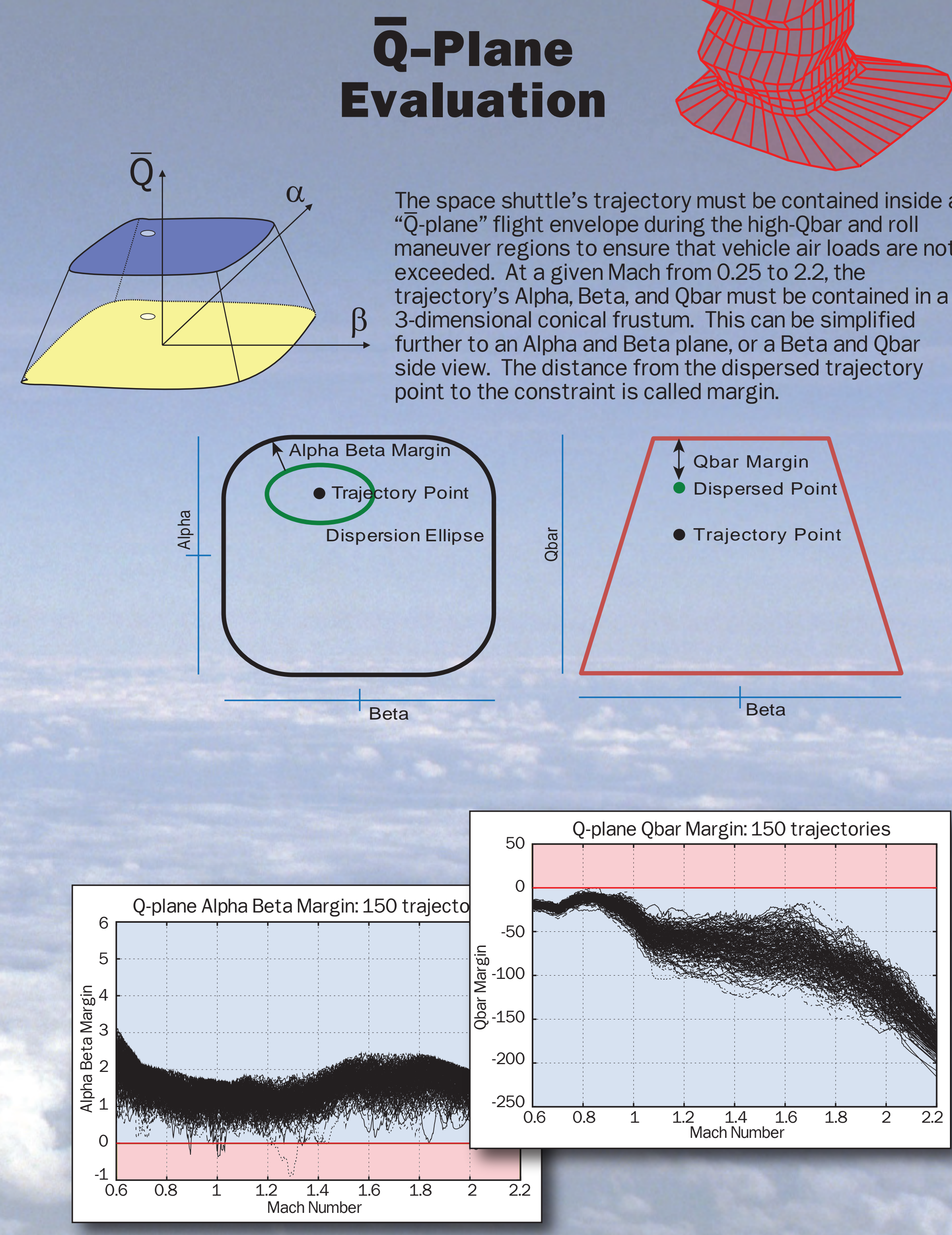